- Of those who applied to graduate school in political science, $87 \%$ were accepted, $67 \%$ were offered financial aid, $60 \%$ had their application fees waived, and $80 \%$ will study political science in graduate school.

- Among those who had not yet applied to graduate school, $46 \%$ said it was still too early but they would apply later; 59\% said they had not decided whether to pursue graduate study in political science; $21 \%$ decided to attend graduate or professional school in other disciplines, e.g. law, history, public policy, and foreign language; and $21 \%$ decided to work for a few years before attending graduate school. (Respondents can check multiple reasons.) As happened last year, none of the students said they had decided not to attend graduate school at all.

2. Noncore schools continue to participate.

- Nineteen percent of the students who responded to the survey were identified by noncore schools. Fifty-six percent of them were identified by $\mathrm{Ph}$.D. institutions, $33 \%$ by MA institutions, and $11 \%$ by BA institutions, suggesting that greater efforts can be made to involve undergraduate institutions in the project.

3. Students are identified and contacted early in their undergraduate years.

- Students participating in the project were at all levels of undergraduate study, including $15 \%$ who were freshmen and $27 \%$ who were sophomores.

4. Most of the students identified have had the opportunity to discuss attending graduate school and pursuing careers in political science with faculty at their schools.

- Forty-four percent of the students who responded to the survey reported meeting individually with a faculty member to discuss future plans (compared to $29 \%$ in 1998) and $53 \%$ of the students reported meeting with other students and faculty in groups to discuss such issues.

\section{9-2000 APSA Minority Fellows Choose Graduate Schools}

APSA funded All Africian-American and Lation fellows who applied to graduate schools were accepted by a graduate program and received outside or departmental funding. Native American Fellow Mark Allen Davis, will receive a $\$ 6,000$ APSA stipend. Also, almost all APSA unfunded minority fellows who applied to graduate schools were accepted by a program and received outside or departmental funding.

\section{Funded Fellows}

\section{African American Fellows}

Elmer Ray Block will attend Ohio State University where he has been granted a fellowship with remission of tuition and fees.

Andra N. Gillespie will attend Yale University, where she has been granted a fellowship with remission of tuition and fees.

Melvin L. Rogers will study at Cambridge University during the 1999-2000 academic year. Beginning in fall 2000, he will attend Yale with a fellowship.

\section{Latino/Latina Fellow}

Sylvia Manzano will attend the University of Arizona, where she has been granted a fellowship and assistantship with remission of tuition and fees.

\section{Native American Fellow}

Mark Allen Davis will attend the University of California, Davis. He has been granted an APSA fellowship.

\section{Unfunded Fellows}

\section{African American Fellows}

Katrina Gamble will attend Emory University, where she has been granted a fellowship from both Emory and her undergraduate institution, Smith College, with remission of tuition and fees.

Aisha Raj will attend Rice University, where she has been granted a Provost's fellowship, which carries full tuition remission for four years.

\section{Latino/Latina Fellows}

Jessica Alas will attend the University of New Orleans, where she has been granted a research assistantship with remission of tuition and fees.

Jose Bocanegra will attend the University of Houston.

Jose A. Ramirez will defer graduate school until 2000.

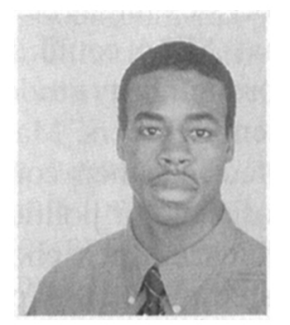

Elmer Ray Block

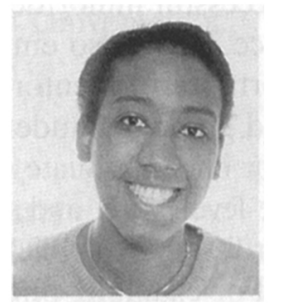

Andra N. Gillespie

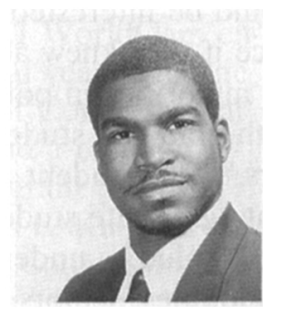

Melvin L. Rogers

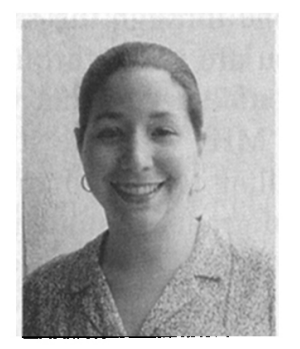

Sylvia Manzano

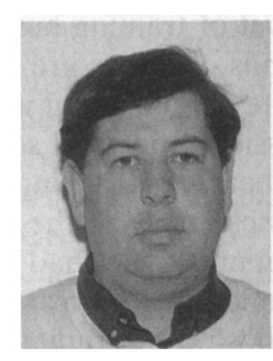

Mark Allen Davis 